\title{
DEGREE OF ASSOCIATION OF BODY MASS INDEX AND WAIST HIP RATIO WITH TYPE 2 DM- A COMPARATIVE STUDY
}

M. Rama Devi1, 0. Padmini², Kali Varaprasad Vadlamani3

\section{HOW TO CITE THIS ARTICLE:}

M. Rama Devi, O. Padmini, Kali Varaprasad Vadlamani. "Degree of Association of Body Mass Index and Waist Hip Ratio with Type 2 DM- A Comparative Study". Journal of Evolution of Medical and Dental Sciences 2015; Vol. 4, Issue 62, August 03; Page: 10858-10863, DOI: 10.14260/jemds/2015/1567

ABSTRACT: BACKGROUND: Of late obesity has become a major malady among adult males and females more so in the latter. The significance of this problem cannot and should not be ignored as it predisposes to several pathological conditions. One such disease is Type II Diabetes Mellitus. Therefore it is imperative to identify obesity related factors which can predict the risk of Diabetes. Over a period of time Body Mass Index (BMI) and Waist Hip Ratio (WHR) have evolved as dependable factors. In this study an attempt has been made to gauge the superiority of one factor over the other in risk prediction. MATERIAL AND METHODS: Our study was done in Gandhi Hospital, Secundarabad over a period of two years (September 2000 to September 2012) 300 diabetics (150 males and 150 females) and 300 non-diabetics controls (150 males and 150 females) attending Out Patient Endocrinology and Medicine departments were considered for the study. BMI and WHR were measured of diabetics and controls according to WHO recommended protocol. Subjects with WHR $>0.9$ in males and WHR $>0.8$ in females were taken to be obese. The degree of sensitivity and specificity of both parameters were calculated and tables prepared. CONCLUSION: Most sensitive indicator for predicting the risk of onset of Diabetes in males is zCXs BMI>25 and in females is WHR>0.8. Hence once these limits are crossed, measures to prevent the onset of Diabetes should be taken in full earnest.

KEYWORDS: Obesity, BMI, WHR, T 2 DM.

INTRODUCTION: In 2008 WHO reported that 1.5 billion adults (about 200 million males and nearly 300 million females) were obese. This is significant because obesity is a major potentially modifiable risk factor for several diseases and syndromes.1,2,3,4

One such disease is type 2 diabetes as it predisposes to insulin resistance. The prevalence of diabetes is 2.9 times higher in overweight individuals (BMI 27.8 in males and 27.3 in females) than in normal weight subjects of 25 to 75 years. ${ }^{5}$ for a given BMI, Asian Indians have higher fat percentage compared to Caucasian subjects (Banerjee et al 1999)..$^{5}$ Hypertrophic intra-abdominal fat cells release fatty acids and cytokines into the portal flow to the liver and with subsequent effects on insulin resistance. Extra fat, particularly in the liver, activates resident macrophages, the immune cells living there.

These macrophages then release LTB4 and other immune signaling molecules stimulate an influx of new macrophages. Then, in a positive feedback loop, the newly arriving macrophages also get activated and release even more LTB4 in the liver. When inflammation becomes chronic, as is the case in obesity, all of this extra LTB4 starts activating other cells, too. Like macrophages, nearby liver, fat and muscle cells also have LTB4 receptors on their cell surfaces and are activated when LTB4 binds them. Now, in obesity, those cells become inflamed as well, rendering them resistant to insulin. ${ }^{6}$ 
High proportion of upper-body fat or abdominal fat independent of overall obesity is recognized as an important component in the insulin resistance linked to obesity and Diabetes Mellitus Type 2. Abdominal fat deposition is hormonally controlled by secretion of adipokinase which may impair glucose tolerance. Abdominal obesity, measured by an elevated WHR is shown to be a strong risk factor for Diabetes Mellitus Type 2.7 from clinical perspective, central obesity (Approximated by waist circumference or waist/hip ratio) is known to provide more information than general Body Mass Index. ${ }^{8}$ The standard epidemiological translation of BMI, WC and WHR are important tools used for anthropometric measures. Waist circumference and waist to hip ratio have been used as measures of central obesity, whereas BMI has been used as a measure of general obesity. ${ }^{9}$ our study was done with the idea of comparing the degree of risk prediction between BMI and WHR as such and of seeing which a better indicator among the genders.

MATERIAL AND METHODS: Our study was a descriptive observational study, done in Gandhi medical college, Secundarabad, over a period of two years from September 2000 to September 2012. A systematic random sample was taken where in every third known diabetic patient who attended the outpatient departments of Medicine and Endocrinology was chosen until 150 males and 150 females with Type 2 Diabetes were obtained. 300 non-Diabetics i.e. 150 males and 150 females were selected by the same systematic random sample to be used as controls.

\section{Demographic data:}

\section{WHO recommended Standard Protocol. ${ }^{10}$ was followed:}

\section{This Protocol can be Summarized as Outlined Below:}

- Measure the waist circumference at the end of several consecutive natural breaths, at a level parallel to the floor, midpoint between the top of the iliac crest and the lower margin of the last palpable rib in the mid axillary line.

- Measure the hip circumference at a level parallel to the floor, at the largest circumference of the buttocks.

- Make both measurements with a stretch-resistant tape that is wrapped snugly around the subject, but not to the point that the tape is constricting. Keep the tape level and parallel to the floor at the point of measurement.

Males with WHR of 0.9 and above and Females with WHR of 0.8 and above were taken as centrally obese individuals and considered for study. Following this data analysis was done by calculating the sensitivity and specificity of the tests i.e. WHR and BMI and tables prepared.

A Sensitive test helps rule out disease (When the result is negative). (Sensitivity rule out or "Snout") 11,12,13 If the test is highly sensitive and the test result is negative you can be nearly certain that they don't have the disease.

Sensitivity $=$ True positives $/($ True positive + false negative $)$

Sensitivity $=\mathrm{TP} / \mathrm{TP}+\mathrm{FN} \times 100$

Specificity $=\mathrm{TN} / \mathrm{TN}+\mathrm{FP} \times 100$

CONCLUSION: In males the most sensitive test for indicating DM is BMI>25. Though $\mathrm{BMI}>30$ is indicative of obesity our study shows that male subjects whose BMI crosses 25 should be targeted for DM control and preventive measures. The second best indicator is WHR >0.9. In females the most 
sensitive test for indicating DM is WHR $>0.8$. Hence, irrespective of their BMI values females whose WHRs are more than 0.8 should be subjected to preventive and control measures. (Tables: 1,2,3,4,5,6,7,8)

\section{MALES:}

\begin{tabular}{|c|c|c|c|}
\hline WHR>0.9 & DM+ & DM- & Total \\
\hline WHR+ & 64 & 26 & 90 \\
\hline WHR- & 86 & 124 & 210 \\
\hline Total & 150 & 150 & 300 \\
\hline & Table 1: Comparison of WHR between Male \\
diabetics and Non-diabetics.
\end{tabular}

Sensitivity (Sn) $=64 / 64+86 \times 100=42$ specificity $(S p)=124 / 124+26 \times 100=83$

\begin{tabular}{|c|c|c|c|}
\hline BMI $>\mathbf{3 0}$ & DM+ & DM- & Total \\
\hline BMI+ & 21 & 7 & 28 \\
\hline BMI- & 129 & 143 & 272 \\
\hline Total & 150 & 150 & 150 \\
\hline Table 2: Comparison of BMI between Male diabetics \\
and Non-diabetics. \\
\hline
\end{tabular}

Sn. $=21 / 21+129 \times 100=14$ Sp. $=143 / 143+7 \times 100=95$

\begin{tabular}{|c|c|c|c|}
\hline BMI>25 & DM+ & DM- & Total \\
\hline BMI+ & 90 & 74 & 164 \\
\hline BMI- & 60 & 76 & 136 \\
\hline Total & 150 & 150 & 150 \\
\hline
\end{tabular}

Table 3: Comparison of BMI between Male diabetics and Non-diabetics.

Sn. $=90 / 90+74 \times 100=54.8$ Sp. $=76 / 76+74 \times 100=50.6$

\section{FEMALES:}

\begin{tabular}{|c|c|c|c|}
\hline WHR>0.8 & DM+ & DM- & Total \\
\hline WHR+ & 87 & 43 & 130 \\
\hline WHR- & 63 & 107 & 170 \\
\hline Total & 150 & 150 & 300 \\
\hline
\end{tabular}

Table 4: Comparison of WHR between Female diabetics and Non-diabetics.

Sn. $=87 / 87+63 \times 100=58$ Sp. $=107 / 107+43 \times 100=71.3$ 


\begin{tabular}{|c|c|c|c|}
\hline BMI>30 & DM+ & Dm- & Total \\
\hline BMI+ & 12 & 4 & 16 \\
\hline BMI- & 138 & 146 & 284 \\
\hline Total & 150 & 150 & 300 \\
\hline
\end{tabular}

\section{Table 5: Comparison of WHR between Female}

diabetics and Non-diabetics.

Sn. $=12 / 12+138 \times 100=8$ Sp. $=146 / 146+4 \times 100=97.3$

\begin{tabular}{|c|c|c|c|}
\hline BMI>25 & DM+ & DM- & Total \\
\hline BMI+ & 78 & 50 & 128 \\
\hline BMI- & 72 & 100 & 172 \\
\hline Total & 150 & 150 & 300 \\
\hline
\end{tabular}

Table 6: Comparison of BMI between Female

diabetics and Non-diabetics.

Sn. $78 / 78+72 \times 100=52$ Sp. $100 / 100+50 \times 100=66.6$

\section{SUMMARY TABLES:}

\begin{tabular}{|c|c|c|}
\hline & Sensitivity & Specificity \\
\hline WHR $>0.9$ & 42 & 83 \\
\hline BMI $>30$ & 14 & 95 \\
\hline BMI $>25$ & 54.8 & 50.6 \\
\hline \multicolumn{2}{|r|}{ Table 7: MALES: Results. } \\
\hline
\end{tabular}

\begin{tabular}{|l|l|l|}
\hline & Sensitivity & Specificity \\
\hline WHR $>0.8$ & 58 & 71.3 \\
\hline BMI $>30$ & 8 & 97.3 \\
\hline BMI $>25$ & 52 & 66.6 \\
\hline \multicolumn{2}{|l|}{ Table 8: FEMALES: } & Results. \\
\hline
\end{tabular}

DISCUSSION: The risk of type 2 diabetes in adults increases continuously with increasing obesity, and decreases with weight loss. A careful analysis of the relationship between obesity and adult onset diabetes confirms that abdominal obesity is an important risk factor, even after controlling for age, smoking and family history. Since waist circumference correlates more closely with abdominal adipose tissue than BMI, the association between indicators of such obesity (e.g., waist circumference and waist-hip ratio) has been studied extensively in the last two decades. Though all anthropometric measures (BMI, waist circumference, waist-hip ratio and waist-height ratio) performed similarly in predicting risk the degree of prediction varied among different studies.

Interestingly our study shows that there is a definite difference in the degree of prediction of risk of developing DM by the two parameters namely BMI and WHR among the genders. Former is a better indicator in males and the latter is a better indicator in females. 


\section{ORIGINAL ARTICLE}

\section{REFERENCES:}

1. Atkintewe TA Adetuibi A: obesity and hypertension in Diabetic Nigerians Tropical Geog raphic Medicine 1986, 38(2): 146-149.

2. Beegon R, Niaz Ma, singh RB; Diet, central obesity and prevalence of hypertension in the urban population of south India Centre of Nutrition Research, Moradabad, India.

3. Foster C, Rotimi C. hypertension, Diabetes and obesity in Barbados: Findings from a recent population based survey. Ethnic Diseases 1993, 3(4): 404-412.

4. Cassano PA, Segal MR Vokonas PS Weiss ST: Body fat distribution blood pressure and hypertension Ann Epidemiology 1990:1:33-481).

5. Dietary fiber and energy regulation Britt Burton-Freeman Amgen, Incorporated, Thousand Oaks, CA 91320-1799.

6. Bannerji et al 1991Body Composition, Visceral Fat, Leptin, and Insulin Resistance in Asian Indian Men*Mary Ann Banerji, Nuzhat Faridi, Rajesh Atluri, Rochelle l. Chaiken, and Harold e. Lebovitz, Department of Medicine, State University of New York Health Science Center, Brooklyn, New York 11203.

7. https://health.ucsd.edu/.../2015-02-23-type-2-diabetes-and-obesity-molec...February 23, 2015 Heather Buschman, PhD).

8. Lahti-Koski et al 2000, M Pietinen manisto S and Vartiniani N E "Ttrends in WHR and its determinants in adults in Finland from 1987 to 1997" American journal of clinical nutrition 72(6) $1436-1444$.

9. Prognostic impact of body weight and abdominal obesity in..

www.academia.edu/.../Prognostic_impact_of_body_weight_and_abdomi...Am J Epidemiol 1998; 148:1187- 94. 21. Molarius A, Seidel JC, Sans S, et al. Waist and hip circumferences, and waist-hip ratio in 19 populations of the WHO.

10. WHO recommended standard protocol (WHO, 1995: WHO, 2000a: WHO/FAO, 20032).

11. Medical Statistics Laboratory, Imperial Cancer Research Fund, London WC2A 3PX,Douglas G Altman, head, Department of Public Health Sciences, St George's Hospital Medical School, London SW17 OREJ Martin Bland, reader in medical statistics BMY 1994;308:1552.

12. Bi variate analysis of sensitivity and specificity produces informative summary measures in diagnostic reviews Johannes B. Reitsma, Afina S. Glas, Anne W. S. Rutjes, Rob J. P. M. Scholten, Patrick M. Bossuyt, Aeilko H. Zwinderman.

13. The dilemma of sensitivity versus specificity in computer-interpreted acute myocardial infarction: Paul, PhD, W. Douglas Weaver, MD. 


\section{ORIGINAL ARTICLE}

\section{AUTHORS: \\ 1. M. Rama Devi \\ 2. O. Padmini \\ 3. Kali Varaprasad Vadlamani \\ PARTICULARS OF CONTRIBUTORS:}

1. Associate Professor, Department of Physiology, Gandhi Medical College, Secunderabad.

2. Associate Professor, Department of Physiology, Gandhi Medical College, Secunderabad.

3. Associate Professor, Department of Orthopaedics, Osmania Medical College, Secunderabad.

FINANCIAL OR OTHER

COMPETING INTERESTS: None

\section{NAME ADDRESS EMAIL ID OF THE} CORRESPONDING AUTHOR:

Dr. M. Rama Devi,

1-1-565, Raghavendra Apartments, New Bakaram, Musheerabad,

Hyderabad-500002.

E-mail:drramajvv@gmail.com

Date of Submission: 26/06/2015.

Date of Peer Review: 27/06/2015.

Date of Acceptance: 25/07/2015.

Date of Publishing: 03/08/2015. 